\title{
Mapeamento Patentário Sobre Veículos Cosmonáuticos no Brasil
}

\author{
Patentary Mapping on Cosmonautical Vehicles in Brazil
}

\author{
Maria Elisa Marciano Martinez ${ }^{1,2}$ \\ Marcello Carvalho dos Reis ${ }^{3,4}$ \\ Claus Franz Wehmann ${ }^{5}$ \\ ${ }^{1}$ Instituto Nacional da Propriedade Industrial, São Paulo, SP, Brasil \\ ${ }^{2}$ Universidade de São Paulo, São Paulo, SP, Brasil \\ ${ }^{3}$ Meteora, Fortaleza, CE, Brasil \\ ${ }^{4}$ Instituto Federal do Ceará, Fortaleza, CE, Brasil \\ ${ }^{5}$ Universidade Federal do Ceará, Fortaleza, CE, Brasil
}

\begin{abstract}
Resumo
O acesso ao espaço é reconhecido como um fator estratégico para a indústria aeroespacial, fato este que gera uma grande aceleração no desenvolvimento dessa indústria desde a Segunda Grande Guerra e, em sua totalidade, feita com a contribuição dos governos, seja em cooperação ou de forma autônoma. Assim, os projetos espaciais estão sendo transferidos para o setor privado devido ao surgimento de várias empresas focadas no desenvolvimento de tecnologias de baixo custo para acesso ao espaço. Dessa forma, com a utilização da análise patentária, estudou-se a presença da indústria aeroespacial no Brasil e sua influência, avaliando-se o conjunto de tecnologias que vão desde a infraestrutura para o lançamento de um foguete, o próprio foguete até a carga útil que constitui o desenvolvimento da área aeroespacial. Conclui-se que o mapeamento patentário para veículos cosmonáuticos é uma ferramenta viável para monitoramento e gestão da tecnologia, já que os documentos patentários são ricas fontes de informação técnica.
\end{abstract}

Palavras-chave: Veículo Cosmonáutico. Mapeamento de Patentes. Documento Patentário.

\begin{abstract}
Access to space is recognized as a strategic factor for the aerospace industry, a fact that has generated a great acceleration in the development of this industry since the Second World War and, in its entirety, made with the contribution of governments, either in cooperation or autonomously. Thus, space projects are being transferred to the private sector, due to the appearance of several companies focused on the development of low-cost technologies for access to space. Thus, with the use of patent analysis, the presence of the aerospace industry in Brazil and its influence was studied, evaluating from the infrastructure for launching a rocket, the rocket itself, the payload that constitutes the development in the aerospace field. It is concluded that patent mapping for cosmonautic vehicles is a viable tool for monitoring and managing technology, since patent documents are rich sources of technical information.
\end{abstract}

Keywords: Cosmonautic Vehicle. Mapping of Patents. Patent Document.

Área Tecnológica: Prospecções Nacionais. Outros. 


\section{Introdução}

O acesso ao espaço é reconhecido como um fator estratégico de grande importância. A tecnologia é desenvolvida desde a Segunda Grande Guerra e, em sua totalidade, feita com a contribuição dos governos, seja em cooperação ou de forma autônoma. Entre esses programas estão os mais antigos, como o americano e o russo, e os programas mais recentes, como o indiano. Com o advento das telecomunicações e o crescimento exponencial das bandas de internet e celular, a necessidade de satélites tem se apresentado como um mercado a ser explorado com o desenvolvimento de lançadores de baixo custo. Assim, os projetos espaciais estão sendo transferidos para o setor privado pelo fato de várias empresas estarem focadas no desenvolvimento de tecnologias de baixo custo para acesso ao espaço, como SpaceX, Blue Origin, Rocket Lab, Firefly space system, Vector space system (BRAUN, 2019).

Paralelamente a esses desenvolvimentos, a miniaturização dos circuitos e a capacidade de processamento desenvolvida ao longo das últimas décadas tornaram possível um novo conceito de exploração do espaço pela utilização não mais de gigantescos equipamentos, de algumas toneladas, mas de pequenos artefatos de alguns quilos: os microssatélites. A vantagem dos microssatélites não está em ter o melhor desempenho em termos de largura de banda ou de amostragem de sinal, pois isso não é compatível com as grandes restrições ao tamanho do satélite. Porém, quando usado em redes ou constelação, os microssatélites são capazes de fornecer melhor resolução temporal a preços acessíveis (CAMPOS; QUEIROZ, 2017; CGEE, 2018).

Em um cenário de cooperação internacional, com considerável acesso a informações de tecnologias críticas, nas próximas décadas, em termos de órbita baixa terrestre LEO, haverá nivelamento entre os fornecedores de serviço com a utilização de pequenas naves espaciais (microssatélites) e de lançadores (PORTZ, 2004). Este ambiente é favorável ao desenvolvimento de indústrias de tecnologia de ponta e a presença destas é um indicador do desenvolvimento de uma região.

As Patentes são elementos-chave para medir os avanços tecnológicos nos países e o impacto delas no desenvolvimento. Com o resultado econômico da aplicação de Pesquisa, Ciência e Tecnologia sendo incorporado ao processo produtivo, a patente representa um ativo e um recurso competitivo à disposição das organizações, propiciando o domínio da exploração monopolística de dado produto ou processo produtivo, privilégio este capaz de criar ou de adicionar valor à riqueza das empresas (FERREIRA; GUIMARÃES; CONTADOR, 2009). As patentes, embora sejam um dos menos midiáticos, representam de forma concreta a criação e a difusão do conhecimento na atividade produtiva. Elas podem ser consideradas um indicador de CT\&I, ou seja, um dado estatístico valioso para elaborar panoramas, cenários, tendências sobre o avanço científico e tecnológico de uma determinada temática e subsidiar a tomada de decisão e o planejamento em políticas públicas ou estratégias organizacionais, além de medir bens intangíveis (FARIA; BESSI; MILANEZ, 2014). Elas também refletem a aplicação do conhecimento em inovação, além de ser uma das mais antigas formas de proteção da propriedade intelectual, cuja finalidade é incentivar o desenvolvimento econômico e tecnológico, recompensando a criatividade (MENDONÇA et al., 2018). 
O Brasil tem um extenso potencial científico e tecnológico, demostrado ao alcançar o $13^{\circ}$ lugar em publicações científicas no âmbito internacional. No entanto, há uma defasagem entre a potencialidade e a efetiva inovação do país. De fato, embora o Brasil ocupe o $13^{\circ}$ lugar em publicações de pesquisa no mundo, ele se encontra na 69a posição entre 127 países em termos de Inovação. Com relação às patentes, considerando os depósitos efetuados no Instituto Nacional da Propriedade Industrial (INPI), verifica-se que 74\% pedidos de 2017 foram depositados por estrangeiros (ORTIZ, 2019).

As patentes são fundamentais na análise da aplicação e no direcionamento das pesquisas científicas, é por meio delas que os países desenvolvem novas tecnologias para conquistar espaço no mercado mundial, por isso, o avanço tecnológico do Brasil pode possibilitar melhores condições de produtividade industrial e competitividade no mercado internacional (MENDONÇA et al., 2018).

Este trabalho utiliza-se da análise patetaria para analisar a presença da indústria aeroespacial no Brasil e sua influência. O conjunto de tecnologias que vão desde a infraestrutura para o lançamento de um foguete, o próprio foguete até a carga útil (Satélites, sondas espaciais, Observatórios, estações espaciais, etc.) constituem desenvolvimentos da área aeroespacial. Normalmente devido ao alto risco e aos requisitos de segurança exigidos, essas tecnologias são o resultado de alto investimento em pesquisas. Nesse aspecto, um parafuso desenvolvido para realizar uma função específica no foguete, como explodir em uma situação controlada, permitindo a separação dos boosters, é resultado de investimento em materiais especiais, formas de fabricação, estudos de características de explosivos etc. O retorno desses investimentos pode vir de situações bem distantes do espaço. Os chamados spinoffs permitem que a tecnologia desenvolvida para imagens em 3D em um módulo em Marte possa ser usado em cirurgias cerebrais (LOCKNEY et al., 2017); ou um polímero que pode ser usado na fabricação de válvulas cardíacas (LOCKNEY et al., 2019).

Como observado, a cadeia de tecnologia abrange desde objetos em terra até naves que se deslocarão a velocidades de $48.280 \mathrm{~km} / \mathrm{h}$ (velocidade da Voyger 1) a milhares de $\mathrm{km}$ de distância da terra (19,3 bilhões de quilômetros). Diante do exposto, ressalta-se que o foco deste estudo é:

\section{Veículo cosmonáutico;}

1. 1. Equipamento ou suas peças, especialmente adaptados para serem instalados em veículos espaciais (cosmonáuticos);

1. 2. Satélites e seus sistemas; Veículos interplanetários;

1. 3. Lançadeiras espaciais;

1. 4. Sistemas de acoplamento ou de separação de veículos espaciais ou de partes dos mesmos;

1. 5. Aparelhos de guia ou de controle;

1. 6. Disposições ou adaptações de sistemas de propulsão;

1. 7. Proteção térmica;

1. 8. Veículos extraterrenos;

2. Equipamento em terra para veículos;

3. Observação ou acompanhamento do curso do veículo cosmonáutico;

4. Sistemas para reentrar na atmosfera da Terra; $e$

5. Equipamento no espaço para veículos ou estações. 
O primeiro item se refere aos sistemas de chegada ao espaço como foguetes em sua maioria e suas variações (podem partir do solo, de balões, de aviões, de barcos etc.) e aos sistemas que ficarão no espaço, como satélites e sondas interplanetárias como a Mars Orbiter Mission, Sonda da agência espacial indiana. Os subsequentes subitens se referem às partes integrantes desses sistemas, como controle, propulsão etc.

O segundo item se refere aos sistemas de apoio em terra, como base de lançamento, sistemas de rastreio, tanques de combustível etc. O terceiro item se referee ao acompanhamento dos veículos astronáuticos, sejam na trajetória do foguete e suas partes (é necessário o monitoramento para garantir que não causarão danos a terceiros), assim como os satélites em orbitas que dependem de correções de orbita e das naves interplanetárias que precisam ser conduzidas aos seus objetivos. O quarto item engloba sistemas responsáveis pela volta dos veículos à Terra. Sejam foguetes reutilizáveis, satélites e estações espaciais em fim de vida útil, ou sondas com materiais coletados em outros corpos celestes. O último item descreve equipamentos especificamente desenvolvidos para o espaço, como câmeras, sensores etc.

\section{Metodologia}

A metodologia adotada neste artigo é o mapeamento patentário para atividade (PORTER, 1991) com as seguintes etapas: $1^{a}$ etapa: definição dos critérios da busca; $2^{a}$ etapa: realização da busca; $3^{\mathrm{a}}$ etapa: filtrar os documentos pertinentes; e $4^{\mathrm{a}}$ etapa: tratamento dos documentos pertinentes.

A $1^{a}$ etapa consistiu na definição dos critérios da busca que foram: (a) abrangência da busca como sendo o Brasil (BR); (b) a base de dados utilizada neste artigo foi a base de dados do INPI, que é uma base de dados com abrangência nacional (BR) e gratuita; (c) verificação na Classificação Internacional de Patentes (CIP), nesse caso, foi escolhido o subgrupo B64G referente a veículos cosmonáuticos e não foram escolhidas palavras-chave, porque o grupo é bem específico; e (d) o período neste artigo está sem limitação temporal.

$\mathrm{Na} 2^{\mathrm{a}}$ etapa foi realizada a busca com os critérios definidos na $1^{\mathrm{a}}$ etapa, dessa busca foram recuperados 84 documentos patentários.

Em seguida foram lidos os resumos dos documentos encontrados na $2^{\mathrm{a}}$ etapa e filtrados os documentos pertinentes ao foco do trabalho apresentado no final da introdução, que foi a $3^{a}$ etapa. Ao final dessa etapa, resultaram 60 documentos patentários pertinentes ao foco do trabalho.

$\mathrm{Na} 4^{\mathrm{a}}$ etapa, os documentos patentários pertinentes ao foco do trabalho (definidos na $3^{\mathrm{a}}$ etapa) foram tratados de forma a serem obtidos: (i) classificação por tecnologia; (ii) principais países prioritários; (iii) principais depositantes; (iv) origem dos depositantes; (v) status dos documentos patentários; e (vi) número de documentos depositados por ano. 


\section{Resultados e Discussão}

Empregando-se a metodologia descrita acima, foram selecionados 60 documentos patentários pertinentes ao foco do trabalho e distribuídos conforme apresentado na Tabela 1.

A Tabela 1 mostra que os principais documentos patentários são referentes: (a) a veículo cosmonáutico - $65 \%$ dos documentos patentários, seguidos por documentos referentes: (b) a equipamento em terra para veículos - $13 \%$ dos documentos patentários; e (c) à observação ou ao acompanhamento do curso do veículo cosmonáutico - $10 \%$ dos documentos patentários.

Tabela 1 - Classificação dos 60 documentos patentários pertinentes ao foco do trabalho

$\begin{array}{cc}\text { Classificação } & \text { FrEQUÊNCIA } \\ \text { Veículo cosmonáutico } & 39 \\ \text { Equipamento em terra para veículos } & 8 \\ \text { Observação ou acompanhamento do curso do veículo cosmonáutico } & 6 \\ \text { Equipamento no espaço para veículos ou estações } & 4 \\ \text { Sistemas para reentrar na atmosfera da Terra } & 3\end{array}$

Fonte: Elaborada pelos autores deste artigo (2020)

Os documentos patentários referentes a veículo cosmonáutico foram subdivididos, e a Tabela 2 mostra os resultados obtidos. Entre as subdivisões, destacam-se: (a) equipamento ou suas peças, especialmente adaptados para serem instalados em veículos espaciais (cosmonáuticos) $38 \%$ dos documentos patentários; e (b) satélites e seus sistemas; veículos interplanetários - 31\% dos documentos patentários.

Tabela 2 - Classificação dos documentos patentários referentes a veículos cosmonáuticos

$\begin{array}{cc}\text { CLASSIFICAção } & \text { FREQUÊNCIA } \\ \begin{array}{c}\text { Equipamento ou suas peças, especialmente adaptados para serem } \\ \text { instalados em veículos espaciais (cosmonáuticos) } \\ \text { Satélites e seus sistemas; Veículos interplanetários }\end{array} & 15 \\ \text { Lançadeiras espaciais } & 12 \\ \text { Sistemas de acoplamento ou de secparação de veículos } \\ \text { espaciais ou de partes desses veículos } \\ \text { Aparelhos de guia ou de controle } & 4 \\ \text { Disposições ou adaptações de sistemas de propulsão } & 2 \\ \text { Proteção térmica } & 1 \\ \text { Veículos extraterrenos } & 1\end{array}$

Fonte: Elaborada pelos autores deste artigo (2020) 
O país de prioridade do documento mostra onde o depósito do documento patentário foi feito pela primeira vez antes de ser realizado em outros países. Normalmente, ele é realizado no país em que a invenção foi produzida (OCDE, 2009). O Gráfico 1 mostra um comportamento concentrado em relação ao país de origem, uma vez que os três primeiros detêm $70 \%$ dos documentos patentários, sendo eles: $\left(1^{\circ}\right)$ Brasil - 15 documentos patentários (25\%); (2०) Estados Unidos - 14 documentos patentários (23\%); e (3) França - 13 documentos patentários (22\%). De acordo com a Organização para a Cooperação e Desenvolvimento Econômico (OCDE, 2011), os três principais "países" que investem na economia do espaço são: Estados Unidos, União Europeia; e, em terceiro, a França. Corroborando com o fato de os depósitos no Brasil de não residentes serem em sua maioria desses países. Além disso, observa-se que os depósitos de residentes (25\%) normalmente não são depositados em outros país além do Brasil.

Gráfico 1 - Países de origem dos documentos patentários referentes a veículos cosmonáuticos

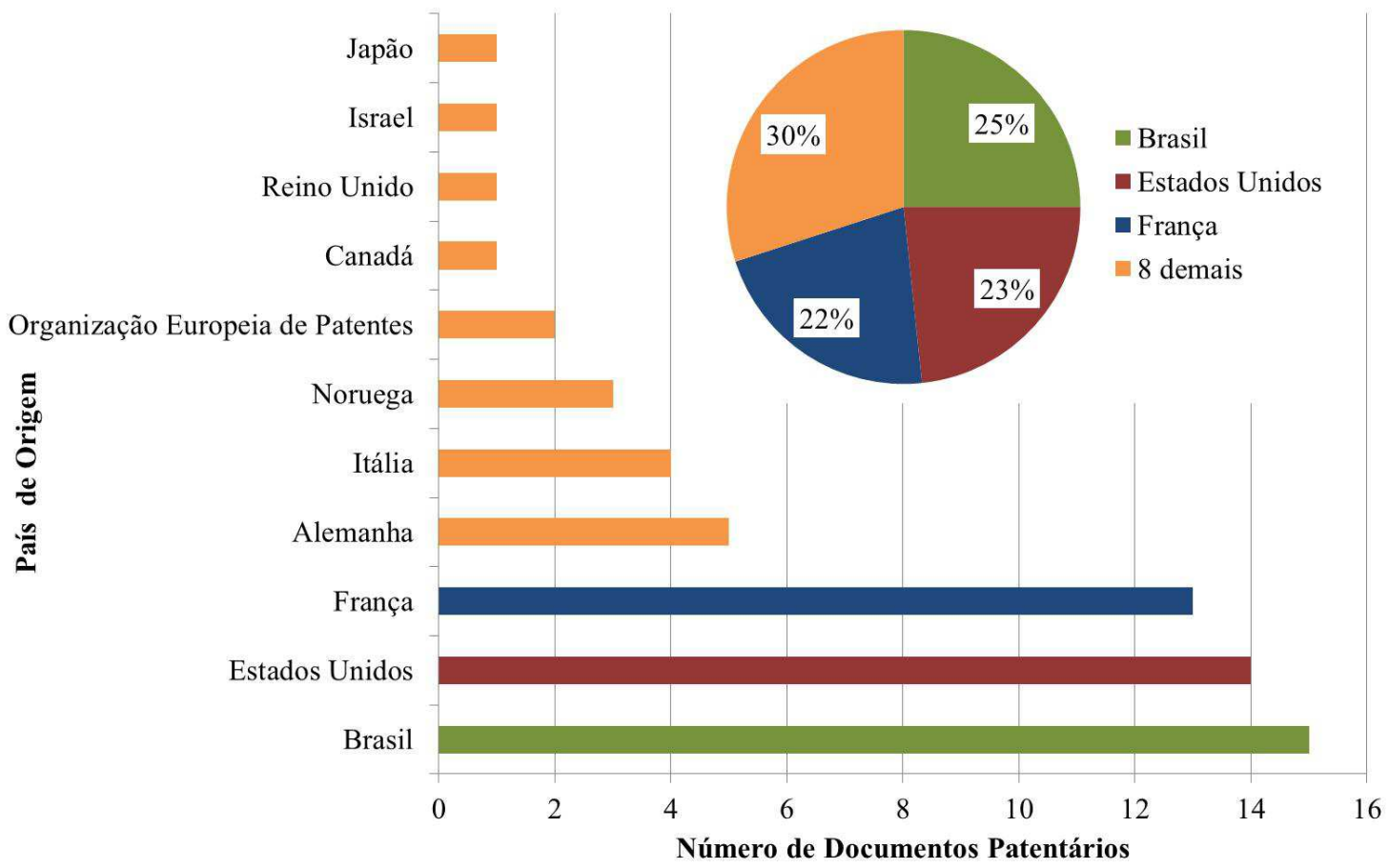

Fonte: Elaborado pelos autores deste artigo (2020)

O Gráfico 2 refere-se ao país do depositante e mostra um comportamento concentrado em relação ao país de origem, uma vez que os três primeiros detêm $70 \%$ dos documentos patentários, sendo eles: (1 $1^{\circ}$ Brasil - 15 documentos patentários (25\%); (2०) França - 13 documentos patentários (22\%); e (3) Estados Unidos - 12 documentos patentários (20\%). Com relação ao país de origem, é possível observar pequenas alterações: a inversão da França e dos Estados Unidos; o aparecimento de Luxemburgo e do Japão; e o desaparecimento da Organização Europeia de Patentes (EP). Entre os 15 documentos patentários que têm como país do depositante o Brasil, o destaque vai para São Paulo (com oito documentos patentários), destes oito, cinco são do Instituto Nacional de Pesquisas Espaciais (INPE). 
Gráfico 2 - Países do depositante dos documentos patentários referentes a veículos cosmonáuticos

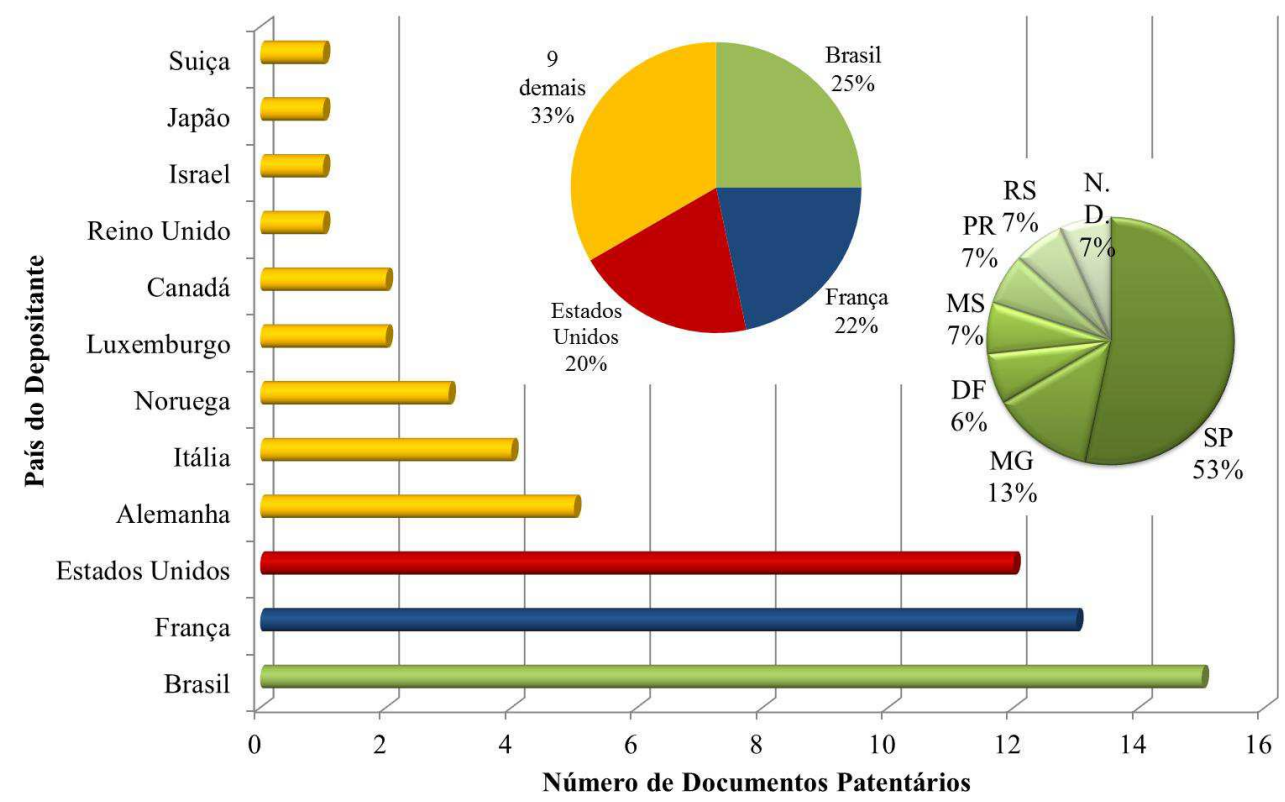

Fonte: Elaborado pelos autores deste artigo (2020)

Já no Gráfico 3 são apontados os 10 primeiros depositantes (que depositaram dois ou mais documentos patentários), assim, nota-se que o comportamento é distribuído, uma vez que os 10 primeiros depositantes detêm $46 \%$ dos documentos patentários, e os 34 demais detêm $54 \%$ dos documentos patentários. Os principais depositantes são: Instituto Nacional de Pesquisas Espaciais (INPE) (empresa brasileira) e The Boeing Company (empresa americana) com cinco documentos patentários depositados cada. Além disso, observou-se que a maioria dos depósitos foi realizada por empresas privadas (74\%), com destaque para a Boeing Company e a Airbus Defence and Space SAS; seguidos pelos inventores independentes (21\%); e pelas entidades governamentais (14\%) do Brasil - Instituto Nacional de Pesquisas Espaciais (INPE) e da França.

Gráfico 3 - Principais depositantes dos documentos patentários referentes a veículos cosmonáuticos

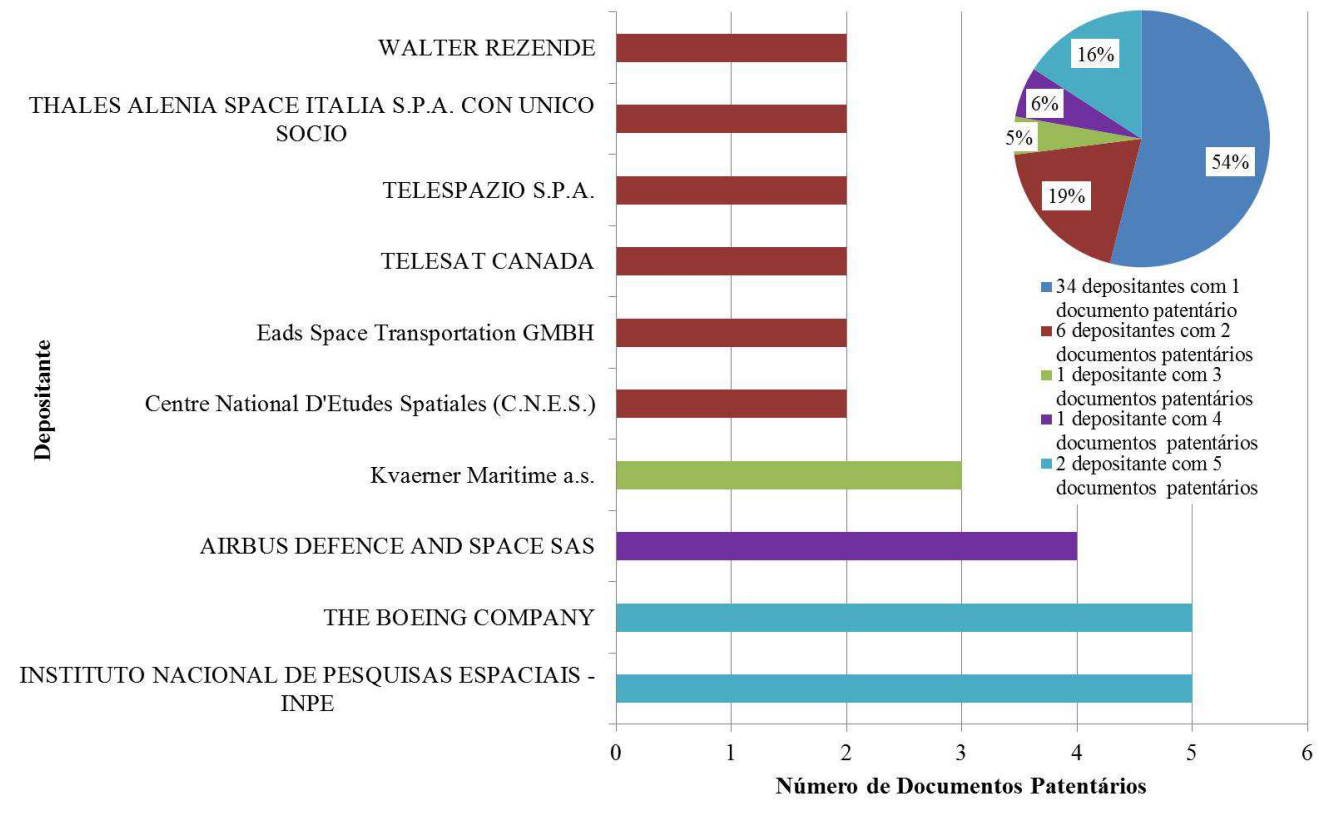

Fonte: Elaborado pelos autores deste artigo (2020) 
O pedido de patente passa por diversas etapas e implica pagamento de diversas taxas $e$ anuidades. Para este artigo, o status do pedido de patente foi resumido como:

a) documento patentário aguardando exame - envolve os documentos patentários desde a data de depósito até a data de início de exame técnico;

b) documento patentário em exame técnico - envolve os documentos patentários desde a data de início de exame técnico até sua decisão;

c) documento patentário arquivado - envolve os documentos patentários que a qualquer momento antes da decisão foram arquivados, por exemplo, por falta de pagamento de anuidade;

d) pedido de patente indeferido - envolve os documentos patentários que foram decididos negativamente, ou seja, foram indeferidos;

e) patente concedida - envolve os documentos patentários que foram decididos positivamente, ou seja, foram deferidos e tiveram sua carta patente expedida; $e$

f) patente concedida e extinta - envolve as patentes concedidas que foram extintas, por exemplo, por falta de pagamento ou por ter perdido o prazo de validade.

O Gráfico 4 mostra o status dos documentos patentários referentes a veículos cosmonáuticos depositados no Brasil, por meio desse gráfico, é possível observar que os documentos patentários, em sua maioria, ou estão arquivados (47\%) ou aguardam exame técnico (30\%). Apesar de todos os documentos estarem em domínio público, efetivamente protegidos no momento tem-se somente as patentes concedidas (3\%); além destes ainda há os documentos que têm uma expectativa de direito (por não terem sido decididos ainda), que são os em exame ou aguardando exame (37\%). Os documentos arquivados merecem certa atenção, pois em algumas situações específicas eles podem ser desarquivados.

Gráfico 4 - Status dos documentos patentários referentes a veículos cosmonáuticos

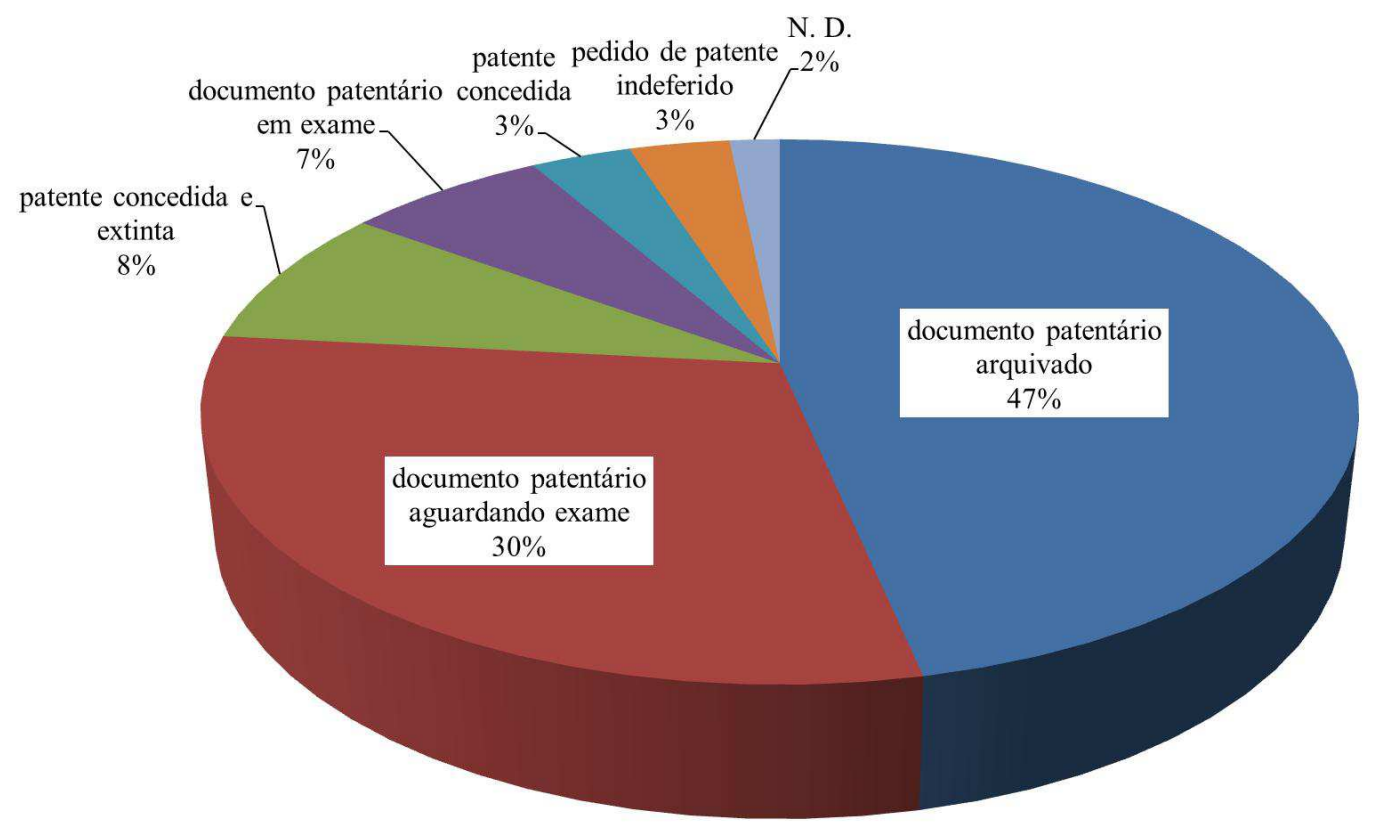

Fonte: Elaborado pelos autores deste artigo (2020) 
No Gráfico 5 encontra-se a evolução temporal dos documentos patentários referentes a veículos cosmonáuticos depositados no Brasil, por meio desse gráfico, é possível observar um comportamento crescente, com dois picos de menor duração (1989/1990 e 1995-1997) e um pico mais longo e com maior número de patentes entre 2013 e 2015 . O primeiro pico de crescimento aconteceu nos anos da construção da Estação Espacial Internacional (EEI) e também com um aumento das atividades espaciais no Brasil com a assinatura do acordo com a china (1988) para o programa Cbers. O segundo pico ocorreu no período em que o ônibus espacial americano Shuttle se acoplou com a estação espacial russa Mir sete vezes (BÔAS; PESSOA FILHO; DAMILANO, 2007), e no âmbito nacional houve a criação da Agência Espacial Brasileira (AEB), assim como os diversos acordos bilaterais com países da américa latina e, em 1997, o primeiro teste do VLS (foguete Brasileiro), quando o país ingressou no programa da estação espacial. E o terceiro e último evento pode estar relacionado com o surgimento do New Space; o surgimento no período de diversas startups na área espacial e um crescimento do respectivo investimento privado (SPACEX, 2020; CARTER, 2019; BLUE ORIGIN, 2020).

Gráfico 5 - Evolução temporal dos documentos patentários referentes a veículos cosmonáuticos

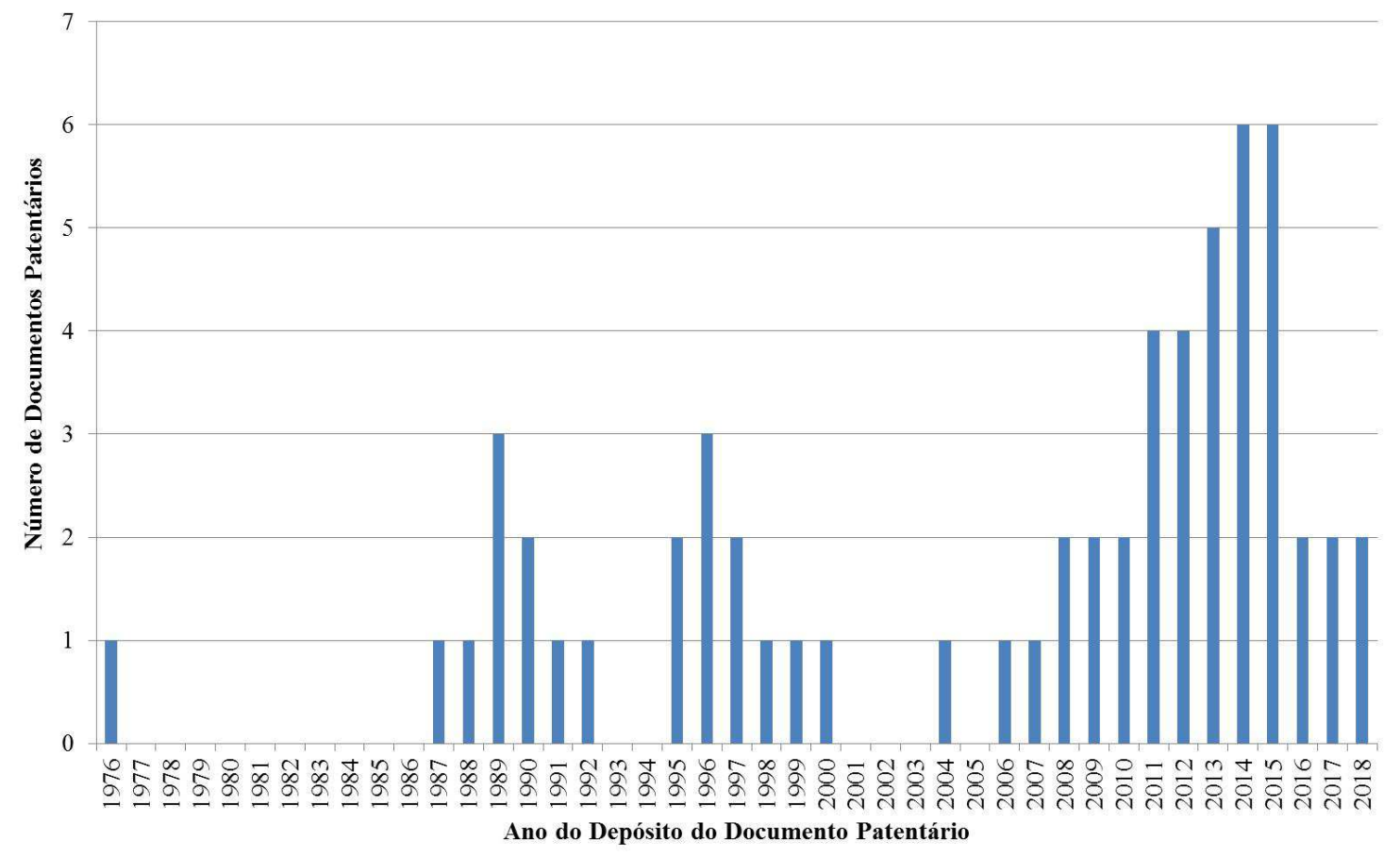

Fonte: Elaborado pelos autores deste artigo (2020)

\section{Considerações Finais}

Este artigo mostrou que o mapeamento patentário, por exemplo, para veículos cosmonáuticos, é uma ferramenta viável para monitoramento e gestão da tecnologia, uma vez que os documentos patentários são as mais ricas fontes de informação técnica.

A partir do exposto, conclui-se que a maioria dos documentos patentários depositados no Brasil sobre veículos cosmonáuticos se refere a tecnologias relacionadas ao próprio veículo cosmonáutico, mais especificamente sobre: equipamento ou suas peças, especialmente adap- 
tados para serem instalados em veículos espaciais (cosmonáuticos), e satélites e seus sistemas; veículos interplanetários. Verifica-se que, em sua maioria, os documentos são de não residentes (75\%), principalmente dos Estados Unidos, e de empresas privadas; enquanto nos depósitos dos residentes o destaque é para instituições governamentais e inventores independentes.

Observou-se, ainda, que o depósito de patentes apresenta uma sazonalidade que está, possivelmente, relacionada com os programas espaciais, nacionais ou estrangeiros. A verificação de tal correlação será abordada em um trabalho futuro.

\section{Referências}

BLUE ORIGIN. Blue Origin. [2020]. Disponível em: https://www.blueorigin.com/. Acesso em: 21 abr. 2020.

BÔAS, D. J. V.; PESSOA FILHO, J. B.; DAMILANO J. G. Formação Continuada de Professores - Curso Astronáutica e Ciências do Espaço - Veículos Espaciais. [S.l.]: Ministério da Ciência e Tecnologia (MCT), Agência Espacial Brasileira (AEB), Programa AEB Escola, 2007. Disponível em: https:/www.gov.br/aeb/pt-br/centrais-de-conteudo/publicacoes/educacional/apostilas-pdf/4veiculos espaciais_manual.pdf. Acesso em: 8 abr. 2020.

BRAUN, J. A nova corrida espacial. Revista Veja Online, [2019]. Disponível em: https://veja.abril. com.br/especiais/a-nova-corrida-espacial/. Acesso em: 8 abr. 2020.

CAMPOS, E. L.; QUEIROZ, K. I. P. M. CubeSat: uma visão global de sua utilização. In: $4^{\circ}$ WORKSHOP DE PESQUISA CIENTÍFICA (WPC 2017), Rio Grande do Norte, Brasil, 2017. Anais [...]. Rio Grande do Norte, Brasil, 2017. Disponível em: https:/www.researchgate.net/ publication/323958450_CubeSat_Uma_visao_global_de_sua_utilizacao. Acesso em: 8 abr. 2020.

CARTER, J. Blue Origin: everything you need to know about the Amazon.com of space. 2019. Disponível em: https://www.techradar.com/news/blue-origin. Acesso em: 21 abr. 2020.

CGEE - CENTRO DE GESTÃO E ESTUDOS ESTRATÉGICOS. CubeSats. Brasília, DF: CGEE, 2018. Disponível em: https://www.cgee.org.br/documents/10195/734063/CGEE_resumoexecutivo_ CubeSats_Web.pdf. Acesso em: 8 abr. 2020.

FARIA, L. I. L.; BESSI, N. C.; MILANEZ, D. H. Indicadores tecnológicos: estratégia de busca de documentos de patentes relacionados à instrumentação aplicada ao agronegócio. Cadernos de Ciência \& Tecnologia, Brasília, DF, v. 31, n. 1, p. 119-144, jan.-abr. 2014. Disponível em: https:// seer.sct.embrapa.br/index.php/cct/article/view/19446. Acesso em: 8 abr. 2020.

FERREIRA, A. A.; GUIMARÃES; E. R.; CONTADOR, J. C. Patente como instrumento competitivo e como fonte de informação tecnológica. Gest. Prod., São Carlos, v. 16, n. 2, p. 209-221, abr.-jun. 2009. Disponível em: http://www.scielo.br/pdf/gp/v16n2/v16n2a05.pdf. Acesso em: 8 abr. 2020.

G1 GLOBO. Sonda da Nasa chega a Marte após 10 meses de viagem. 2014. Disponível em: http://g1.globo.com/ciencia-e-saude/noticia/2014/09/sonda-da-nasa-chega-marte-apos-10-meses-deviagem.html. Acesso em: 8 abr. 2020.

LOCKNEY, D. et al. Contributing writes: Carroll, R. SPINOFF 2019 - Technology Transfer

Program. [S.l.]: NASA, 2019. Washington, D.C. Disponível em: https://spinoff.nasa.gov/Spinoff2019/ pdf/Spinoff2019.pdf. Acesso em: 8 abr. 2020. 
LOCKNEY, D. et al. Contributing writes: Reiny, S. and Healy, A. SPINOFF 2017 - Technology Transfer Program. [S.l.]: NASA, 2017. Washington, D.C. Disponível em: https://spinoff.nasa.gov/ Spinoff2017/pdf/Spinoff2017.pdf. Acesso em: 8 abr. 2020.

MENDONÇA, V. M. et al. Indicadores Nacionais e Internacionais de Ciência, Tecnologia \& Inovação. Cadernos de Prospecção, Salvador, v. 11, n. 5, Edição Especial: VIII ProspeCT\&I, p. 1.293-1.304, dezembro, 2018. Disponível em: https://portalseer.ufba.br/index.php/nit/article/view/27178. Acesso em: 8 abr. 2020.

OCDE - ORGANIZAÇÃO PARA A COOPERAÇÃO E DESENVOLVIMENTO ECONÔMICO.

OECD Patent Statistics Manual. 2009. Disponível em: https:/www.oecd-ilibrary.org/ docserver $/ 9789264056442$-en.pdf?expires $=1584987209 \& \mathrm{id}=\mathrm{id} \&$ accname $=$ guest\&checksum $=77 \mathrm{~F}$ 1F3762BE06556719596CE3F9C9B34. Acesso em: 8 abr. 2020.

OCDE - ORGANIZAÇÃO PARA A COOPERAÇÃO E DESENVOLVIMENTO ECONÔMICO. OECD The Space Economy at a Glance 2011. 2011. Disponivel em: https://www.oecd-ilibrary.org/ economics/the-space-economy-at-a-glance-2011_9789264111790-en. Acesso em: 21 abr. 2020.

ORTIZ, R. M. The Implementation of Intellectual Property in Public University from the Brands of Innovation. PIDCC, Aracaju, SE, v. 13, n. 3, p. 106-129, outubro de 2019. Disponível em: http:// pidcc.com.br/06102019i.pdf. Acesso em: 8 abr. 2020.

PORTER, A. L. Forecasting and management of technology. Estados Unidos: Wiley Series in Engineering and Technology Management, 1991. p. 306-307.

PORTZ, R. Launch Vehicle Design Features For Minimum Cost. In: 40 AIAA/ASME/SAE/ASEE Joint Propulsion Conference and Exhibit. Fort Lauderdale, Florida. 2004. Anais [...]. Fort Lauderdale, Florida. 2004. Disponível em: https://arc.aiaa.org/doi/abs/10.2514/6.2004-3562. Acesso em: 8 abr. 2020.

SPACEX. SpaceX. [2020]. Disponível em: https://www.spacex.com/about. Acesso em: 21 abr. 2020.

\section{Sobre os Autores}

\section{Maria Elisa Marciano Martinez}

E-mail: melisa@inpi.gov.br ORCID: https://orcid.org/0000-0002-8010-869X

Mestre em Engenharia Química pela Universidade de São Paulo (Poli-USP) em 2000.

Endereço profissional: Rua Tabapuã, n. 41, 4 andar, Itaim-Bibi, São Paulo, SP. CEP: 04533-010.

\section{Marcello Carvalho dos Reis}

E-mail: marcello@meteora.com.br

ORCID: https://orcid.org/0000-0002-1132-9034

Mestre em Metrologia pela Universidade Católica do Rio de Janeiro (Puc-Rio) em 2018.

Endereço profissional: Rua Andrade Pertence, n. 42, Catete, Rio de Janeiro, RJ. CEP: 22220-010.

\section{Claus Franz Wehmann}

E-mail: claus.wehmann@ufc.br

ORCID: http://orcid.org/0000-0001-8756-9387

Doutor em Engenharia Aeronáutica e Mecânica pelo Instituto Tecnológico de Aeronáutica (ITA) em 2010.

Endereço profissional: Campus do Pici, Bloco 714, Fortaleza, CE. CEP: 60455-760. 